\title{
Food away from home and the reversal of the calorie intake decline in India
}

\author{
Deepthi E. Kolady ${ }^{1}$ (1) $\cdot$ Shivendra Kumar Srivastava ${ }^{2} \cdot$ David Just $^{3} \cdot$ Jaspal Singh $^{4}$
}

Received: 19 February 2020 / Accepted: 14 September 2020 / Published online: 30 September 2020

(C) The Author(s) 2020

\begin{abstract}
India experienced a consumption puzzle since the 1970s, whereby households' calorie intakes declined over time, despite significant economic growth. This declining trend in calorie intake (consumption puzzle) was reversed for the first time in 2011-12. This is the first empirical study that investigates the relationship between refinements in data collection on food away from home $(\mathrm{FAFH})$ and the trend reversal in per capita calorie intake decline in India. Findings from the study showed that the declining trend in calorie intake in India has been partly due to measurement issues and that correcting for these issues through refinements in data collection for FAFH in 2011-12 had a positive effect on the reversal of the calorie intake decline. India uses per capita calorie intake estimated using data from HCES to define the official poverty line, a benchmark used in designing many social welfare programs. Incorrect estimates of calorie intake will have negative implications on the effectiveness of welfare programs aimed at reducing food insecurity. Findings from this study provide insights for further improvement in data collection regarding household-level consumption expenditures. The study has implications not only for India but also for other countries that use household-level consumption data to understand diets and to design food and nutrition programs.
\end{abstract}

Keywords Calorie consumption puzzle $\cdot$ Calorie intake $\cdot$ Food insecurity $\cdot$ Household consumption expenditure

Deepthi E. Kolady

Deepthi.kolady@sdstate.edu

Shivendra Kumar Srivastava shivendraiari@gmail.com

David Just

drj3@ cornell.edu

Jaspal Singh

punjabimatti82@gmail.com

1 Ness School of Management and Economics, South Dakota State University, Brookings, SD 57006, USA

2 Scientist (Agricultural Economics) ICAR-National Institute of Agricultural Economics and Policy Research, P.B. No. 11305, Dev Prakash Shastri (DPS) Marg, Pusa, New Delhi 110 012, India

3 Dyson Cornell SC Johnson College of Business, Cornell University, Ithaca, NY 14853, USA

4 NITI Aayog, Government of India, New Delhi 110001, India

\section{Introduction}

There is substantive evidence supporting a positive relationship between income growth, poverty reduction, and food consumption expenditure (Deaton and Drèze 2002; Patnaik 2010). Food consumption expressed in kilocalories per capita per day is used to measure and evaluate the changes in global, regional, and national food security (WHO 2019). However, India faced a paradoxical trend in average calorie intake since the 1970s; a decline in per capita calorie consumption, even when the economy was growing, and per capita real incomes were rising (Basu and Basole 2012). The decline in per capita calorie consumption over time, despite the increase in real consumption expenditures, is referred to as the 'consumption puzzle' in India (Chandrasekhar and Ghosh 2003; Deaton and Drèze 2009; Basole and Basu 2015; Duh and Spears 2017).

The 'consumption puzzle' has been the focus of intense debate and discussion during the last three decades due to the high prevalence of undernourishment and micronutrient deficiencies in India (Meenakshi 2016) and its implications for food and nutrition policymaking. Although both England during the Industrial Revolution and China between 1985 and 
1992 experienced stagnant or declining calorie intakes during these periods of economic growth, India's consumption puzzle stood out as it was happening when the calorie intake levels were already low (Eli and Li 2012; Duh and Spears 2017; Rao 2000). Household-level consumption expenditure data is used in India to define the "official poverty line' used in the formulation of welfare programs. Further, per capita calorie intake estimates derived from the Human Development Survey and the Household Consumer and Expenditure Survey (HCES) are used to measure under-nourishment levels in the country. Incorrect estimates of calorie intake will have negative implications on the effectiveness of welfare programs aimed at reducing poverty and food insecurity.

In addition to undernourishment, malnourishment and micronutrient deficiency are also very prevalent in India. As per the HCES data, per capita protein intake decreased from $60 \mathrm{~g}$ during 1993-94 to 57g during 2011-12 while per capita fat intake increased from $35 \mathrm{~g}$ during 1993-94 to $45 \mathrm{~g}$ during 2011-12. As per the data from National Nutrition Monitoring Bureau (NNMB), per capita calorie intake of micronutrients are declining except for Vitamin $\mathrm{A}$ and Vitamin C (NNMB 2012). The effects of undernourishment, malnourishment, and micronutrient deficiency are reflected in the health outcome indicators of the Indian population. As per the National Family Health Survey (NFHS), currently every third child in the country is stunted or underweight, every second child and woman are anemic, and every fourth woman suffers from low body mass index (BMI) (NFHS 2015). Effective targeting of welfare programs is essential for addressing the triple burden of undernourishment, malnourishment, and chronic micronutrient deficiency in India. A secular decline in calorie intake under such circumstance is alarming - especially as financial resources are apparently improving. Correct measurement of per capita calorie intake used to estimate undernourishment and poverty rates in the country are thus of significant importance.

Previous studies have identified potential reasons for India's 'consumption puzzle', including factors such as rural impoverishment (Patnaik 2010), budget squeeze (Basole and Basu 2015), diet diversification (Parapuurathu et al. 2015), urbanization and occupational changes (Eli and Li 2012), decline in energy requirement (Deaton and Drèze 2009), consumers' deliberate selection of luxury goods over food (Banerjee and Duflo 2011), and improvements in the epidemiological environment (Duh and Spears 2017). Data from the India HCES show that foods consumed away from home are an important source of food in both urban and rural areas in India. As per the HCES data, the percent of households consuming food away from home (FAFH) increased from $23 \%$ in 1994 to $45 \%$ in $2011-12$.

Using 1999/2000 HCES data and employing propensity score matching, Smith (2015) showed evidence of measurement error in the accounting of
FAFH and argued it as one of the potential reasons for the 'consumption puzzle' in India. While Smith (2015) brought incorrect estimation of FAFH to the forefront of the 'consumption puzzle' debate in India, her study uses the 1999/2000 round of HCES data which was subjected to intense criticism for methodology and inconsistency (Sen 2000).

In 2011-12, India experienced a reversal in the declining trend of per capita calorie intake for the first time since the $1970 \mathrm{~s}$; there was a $2.7 \%$ increase in per capita calorie intake, from $2034 \mathrm{Kcal} /$ person/day in 2004-05 to $2088 \mathrm{Kcal} /$ person/day in 2011-12 (Fig. 1a, b, and c). This reversal in the trend coincided with refinements in data collection for FAFH in the 2011-12 round of HCES that are used to calculate the calorie intake. Unlike the previous HCES rounds, the collection of information on FAFH was unpacked into three separate categories for the first time in 2011-12: 'number of cooked meals purchased', 'number of cooked meals received free in the workplace', and the 'number of cooked meals received as assistance'. Fiedler and Yadav (2017) used 2007-08 and 2011-12 rounds of HCES data to show evidence of measurement error in estimation of calorie intake from FAFH. They analyzed the impact of survey modifications on calorie intake estimates from FAFH. Although their study showed a substantial increase in the FAFH calorie estimate in 2011-12 round compared to the 2007-08 round, they did not extend their analysis to examine the effect of correcting for measurement error in FAFH calculations on the overall per capita calorie intake estimate in 2011-12.

Given the importance of correct estimation of per capita calorie intake for informed policymaking in India, in this study, we use data from the 2004-05 and 2011-12 rounds of HCES as a natural experiment to investigate the effect of refinements in data collection regarding FAFH on the increased per capita calorie intake in 2011-12. To the best of the authors' knowledge, this is the first empirical study investigating the relationship between the refinement of data collection of FAFH and the trend reversal in the calorie intake decline in India. Findings from this study provide insights for further improvement in data collection on household-level consumption expenditures. Results from the study have implications not only for India but also for other countries that use household-level consumption data to understand diets and to design food and nutrition programs.

\section{Methodology}

\subsection{Data}

The HCES rounds conducted by the National Sample Survey Office (NSSO) every 5 years using a large nationally 
Fig. 1 a The trend in poverty, calorie intake, and

undernourishment in rural India.

b The trend in poverty, calorie intake, and undernourishment in urban India. c The trend in poverty, calorie intake, and undernourishment in all India
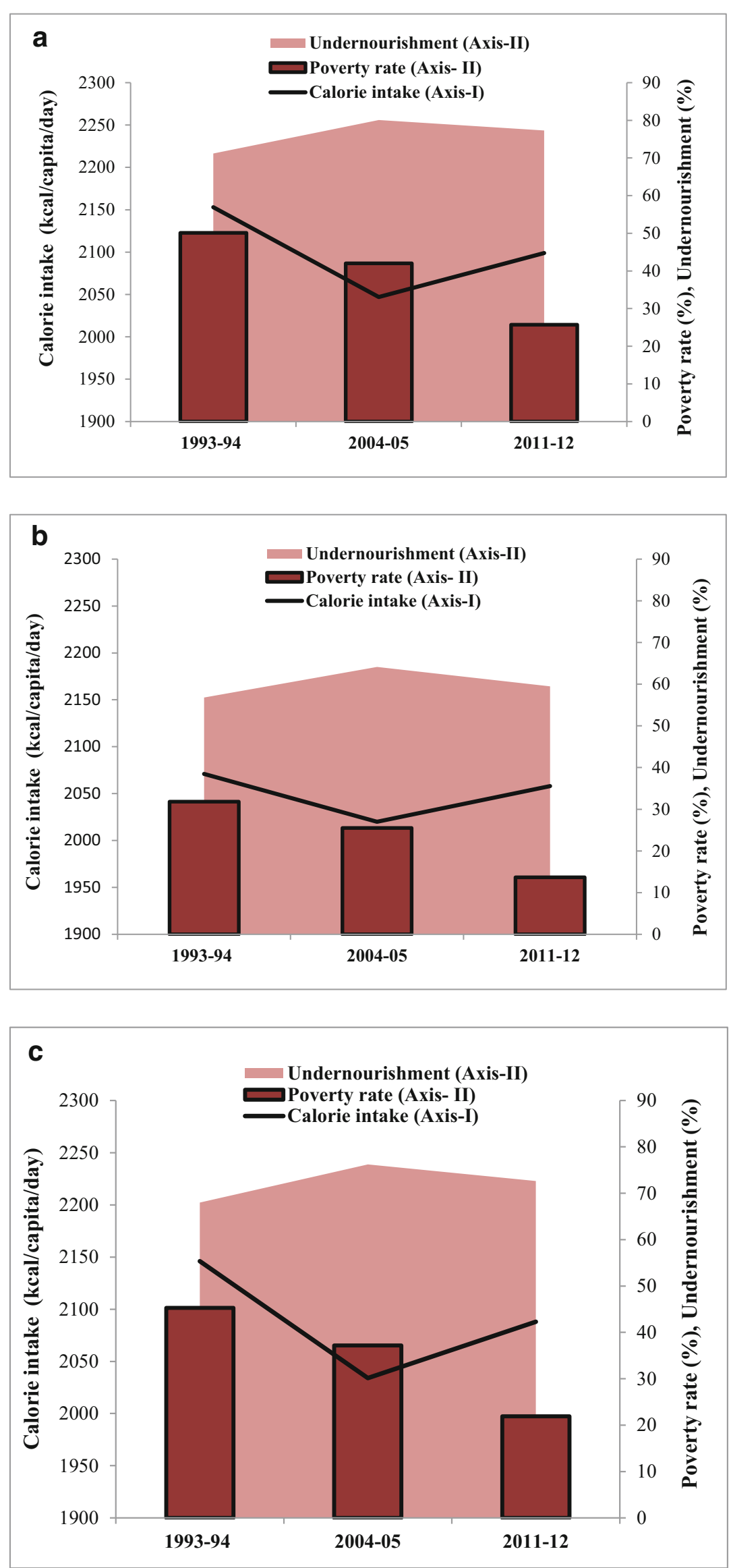
representative sample are considered 'thick' rounds. HCES rounds conducted annually/every 2 years using a relatively small sample are considered as 'thin' rounds and can be subjected to much larger variability. Because of the differences in the sample size and design, a comparison of findings from the 'thick' and 'thin' rounds is not recommended. For example, the 2007-08 round used in Fiedler and Yadav (2017) is a 'thin' round while 2011-12 round is a 'thick' round. The NSSO uses a stratified multi-stage design for HCES data collection. Population weights are provided along with data to convert sample means to population means and we use these throughout the paper.

In comparing HCES from different rounds, it is also important to consider any changes to the survey instrument. In particular, since 2009-10, the HCES canvassed two different survey schedules based on the difference in the recall period. In schedule type I, food items had a 30-day recall period. However, in the type II schedule, a few food items had a 30day recall period, and the rest had a 7-day recall period. Use of the type I schedule ensures continuity with data from previous HCES rounds, which only had data from a 30-day recall period. Use of data from 7-day recall period is expected to improve the efficiency of calorie intake estimates due to the shorter recall period compared to the 30-day recall period. Note that the focus of this study is to analyze the trend in calorie intake, not to obtain a specific and accurate estimate of the magnitude of calorie intake. Hence use of type 1 schedule with 30 day recall period is appropriate for our study.

In this study, we use data from the type I schedules (with 30 day recall period) of 2004-05 and 2011-12 'thick' rounds of HCES conducted by the NSSO. Although we have access to the 2009-10 'thick' round of HCES data, we do not include this in our study as the government considered it an unusual year due to widespread drought, and decided to resample again in 2011-12 (NSSO 2014a). The questions in the survey are grouped into different 'blocks'. Type 1 schedule of HCES has 15 'blocks' of questions for 2004-05 and 2011-12 rounds. Although the main focus of HCES is to collect household consumption and expenditures on food and non-food items, it also collects information on households' demographic and socio-economic characteristics.

\subsection{Study design}

The survey respondent provides individual-level information on meals away from home for each household member and household-level information on the number of meals taken away from home and at home. The 2004-05 and 2011-12 rounds of the HCES collected similar data on the number and type of meals consumed by each household member (Block 4 on the survey schedule: demographic and other particulars of household members) at home and away from home during last 30 days. The meals away from home under Block 4 included the following: free of cost school meals, free of cost meals from the employer, free of cost meals from others, and meals purchased (Table 1). It is evident from Table 1 that among the four sources of FAFH listed in Block 4, the numbers were statistically significantly different only for number of free school meals and number of paid meals, between 2004-05 and 2011-12 rounds. As per Table 1, the number of households reporting consumption of FAFH increased from $34 \%$ in $2004-05$ to $45 \%$ in $2011-12$.

However, information to estimate calorie intake comes from the household level data on consumption from Block 5 of the HCES schedule. It should also be noted here that the use of a household-based measure in calorie estimation (reported in Block 5 at the household level) could lead to measurement error issues due to factors such as the cognitive burden on the interviewee to report a household level quantity by integrating all the individual based information reported in Block 4 (Fiedler and Yadav 2017). The analysis of the Block 5 of HCES type 1 schedules shows that in the 2004-05 round, information to estimate calorie intake from FAFH was contained only in one category, the 'number of cooked meals' (item 303 in the HCES schedule in Block 5). On the other hand, Block 5 of the 2011-12 HCES round had three separate categories for 'cooked meals': 'number of cooked meals purchased' (item 280), 'number of cooked meals received free in the workplace' (item 281), and the 'number of cooked meals received as assistance' (item 282). We consider this unpacking of 'number of cooked meals' (item 303 in Block 5) in 2004-05 into three separate categories in 2011-12 (item 280, 281, and 282 in Block 5) as refinement in data collection and accounting of calories from FAFH (Fiedler and Yadav 2017). Table 2 summarizes the key changes in data collection on FAFH in Block 5, between the 2004-5 and 2011-12 rounds of HCES. In other words, having only an aggregate number for cooked meals in 2004-05 round compared to the unpacked numbers in 2011-12 HCES led to the underreporting of FAFH in 2004-05 HCES. In addition to the three separate categories on the number of cooked meals, the 2011-12 HCES round also collected expenditure values on cooked snacks purchased (item 283 in Block 5) and other processed foods served (item 284 in Block 5). As per our understanding, items 283 and 284 in 2011-12 HCES were possibly included in the "Salted refreshment" (item 301 in Block 5) and the "other processed food" (item 308 in Block 5) categories in the 2004-05 HCES.

Indian Council of Medical Research (ICMR) computes food-item wise nutrient intake (calorie, protein, fat) and provides conversion factors to NSSO. NSSO uses these conversion factors while calculating nutrient intake. For our analysis, the food quantities are converted into kilocalories (Kcal) based on the NSSO report "Nutritional Intake in India, 2011-12"(NSSO 2014b). The nutrient content of each food item in the schedule per unit of quantity or expenditure is given in the NSSO report 
Table 1 Comparing consumption pattern of food away from home (FAFH) between 2004 and 05 and 2011-12 in rural India (Block 4)

\begin{tabular}{lll}
\hline Category (\#/per capita/day) & $2004-05$ round & 2011-12 round \\
\hline Consumption of FAFH (1-Yes, 0-No) & 0.342 & $0.449 * * *$ \\
& $(0.474)$ & $(0.497)$ \\
a. Number of free school meals AFH (\#) & 0.043 & $0.068^{* * *}$ \\
& $(0.105)$ & $(0.128)$ \\
b. Number of employer paid free meals AFH (\#) & 0.003 & 0.003 \\
& $(0.043)$ & $(0.044)$ \\
c. Number of other free meals AFH (\#) & 0.032 & 0.031 \\
& $(0.139)$ & $(0.123)$ \\
d. Number of paid meals AFH (\#) & 0.006 & $0.011 * * *$ \\
& $(0.075)$ & $(0.094)$ \\
Total (a + b + c +d) & 0.084 & $0.112^{* * *}$ \\
Number of observations & $(0.194)$ & $(0.204)$ \\
\hline
\end{tabular}

Mean values were calculated after applying population weights. $* * *$ indicates results from t-tests comparing the mean values between rounds are statistically significant at $1 \%$ levels
(NSSO 2014b). For items having variable food content, average nutrient contents per Indian rupee were given in the report instead of per unit quantity. These quantities multiplied by the value of consumption give the total quantities of nutrients dervied from an item. The ICMR has provided the same conversion factor per meal (1200 kcal/meal) for 2004-05 and 2011-12 HCES rounds, hence calculation method should not be a cause for underreporting of calorie intake for FAFH.

About $69 \%$ of India's population lives in rural areas and poverty and food insecurity levels are high in rural areas (Fig. 1a, and b). Further, most of the changes in occupational structure that potentially attribute to lower calorie intake occur in rural areas (Basu and Basole 2012). Although consumption of FAFH was comparatively higher in the urban sector (in 2004-05), the rural sector witnessed a 7.8 times increase in calorie intake from FAFH between 2004-05 and 2011-12 rounds compared to the 2.3 times increase seen in the urban sector. For these reasons, we focus our analysis on the rural sector in India.

\subsection{Empirical strategy and model}

The joint occurrence of the increase in per capita calorie intake and the improvement in data reporting on FAFH in the 2011-
12 round of HCES data allows us to investigate the effect of refinement of data collection of FAFH on the reversal of the per capita calorie intake decline in India. We hypothesize that due to the improvement in the reporting and accounting of FAFH in the 2011-12 HCES round, households with FAFH in this round will have higher per capita calorie intake than those households without FAFH. Our alternative hypothesis is that due to the improper accounting of FAFH in the 2004-05 HCES round, households with FAFH in this round will have lower per capita calorie intake than those households without FAFH. The effects of different factors on calorie intake have been studied previously (Srivastava and Chand 2017) and comparing the magnitude of FAFH with other determinants is not the focus of this study.

We employ two different approaches to test our hypotheses. First, we use the treatment effect estimator using propensity score matching (PSM) to estimate the average effect of FAFH on per capita calorie intake in each of the HCES rounds (Smith 2015). Second, we use a regression approach to estimate the effect of FAFH on per capita calorie intake while controlling for other factors influencing calorie intake, such as demographic and socio-economic characteristics and diet diversity (Basole and Basu 2015). Use of PSM in this study,
Table 2 Comparing HCES data collection on FAFH in Block 5 between 2004-05 and 2011-12 rounds

\begin{tabular}{lll}
\hline Category & $\begin{array}{l}\text { 2004-05 Round } \\
\text { Type 1 Schedule }\end{array}$ & $\begin{array}{l}\text { 2011-12 Round } \\
\text { Type 1 Schedule }\end{array}$ \\
\hline $\begin{array}{l}\text { Data on number of cooked meals (per capita per 30 days) } \\
\text { Cooked meals }\end{array}$ & Yes & NA \\
Cooked meals purchased & NA & Yes \\
Cooked meals received as free in workplace & NA & Yes \\
Cooked meals received as assistance & NA & Yes \\
\hline
\end{tabular}

NA Not available 
separately for two HCES rounds, one with under-reporting of FAFH and another with refinement in data collection on FAFH, allows us to extend the analysis of Smith (2015) to the two latest HCES 'thick' rounds available and to examine whether refinements in data collection reported in Table 2 will have positive effect on the per capita calorie intake. The use of two different approaches to examining the relationship between per capita calorie intake and FAFH will allow us to test the robustness of the results. To avoid measurement error issues due to outliers, we have dropped observations which were more than three times the standard deviation above the mean in each round (1765 observations in total). We did not drop observations which were more than three times standard deviations below the mean ( 85 observation in total), as we were not sure whether those values were due to acute undernourishment or measurement issues.

\subsection{Treatment effect model using PSM}

It is evident that the HCES data we use in our study is an observed sample of subjects where some have taken FAFH, and some have not. Simply taking the difference in sample means will not give us the correct estimate of the effect of FAFH because we observe only one of the two potential outcomes for each subject: calorie intake with or without the consumption of FAFH, not both outcomes per respondent (Smith 2015). To address this missing data problem, we have created a dummy variable representing whether anybody in the household has taken FAFH or not. The dummy variable $\mathrm{DFAFH}_{i}$, where $\mathrm{i}$ is an index for household and $\mathrm{t}$ is the year of HCES, can be considered as a treatment that takes the value of 1 if households report consumption of FAFH and zero otherwise. Our interest here is to estimate the effect of $D F A F H_{i t}$ on the outcome variable, per capita calorie intake $\left(P C C I N T A K E_{i t}\right)$. In an ideal experiment to estimate the treatment effect, we would observe a subject with the outcome with and without treatment (PCCINTAKE $E_{i t 1}$ with $D F A F H_{i t}=1$ and $P C C I N T A K E_{i t 0}$ with $\left.D F A F H_{i t}=0\right)$. We will then average the difference between PCCINTAKE $E_{i t 1}$ and $P C C I N T A K E_{i t 0}$ across all the subjects in our sample to obtain an average treatment effect (ATE), which is a measure of the average effect of FAFH on PCCINTAKE.

However, our study sample consists of observational data, where treatment status is not randomized. The use of treatment effect estimators allows for covariates to be related to the potential outcome and the treatment and to estimate the effect of treatment $\left(D F A F H_{i t}\right)$ on the outcome (PCCINTAKE $\left.E_{i t}\right)$ using observational data. We also use the treatment effect estimators to estimate the average treatment effect on the treated (ATET) among the subjects that received the treatment $\left(D F A F H_{i t}\right)$. Estimating ATE and ATET separately for each round of HCES and comparing the results will allow us to examine the effect of FAFH on the observed increase in PCCINTAKE $E_{i t}$. Smith (2015) used PSM with the 1999/2000 HCES data to show evidence of underreporting of FAFH and argued that this measurement error could be one of the reasons for the 'consumption puzzle'.

For the treatment effect model, we used PCCINTAKE $E_{i t}$ as the outcome variable and $D F A F H_{i t}$ as the treatment variable. The explanatory variables used in the logit model for the regression of $D F A F H_{i t}$ in the treatment model are presented and defined in Table 3. We used TEFFECTS PSMATCH in STATA 15 to estimate the ATE and ATET by matching each subject to a single subject with the opposite treatment whose propensity score was closest.

\subsection{Regression approach}

We are particularly interested in examining the causal association between $D F A F H_{i t}$ and PCCINTAKE $E_{i t}$. The empirical model we use is given below:

$$
\begin{aligned}
\log P C C I N T A K E_{i t}= & \alpha_{0}+\alpha_{1} D_{F A F H}+\theta X_{i t}+\gamma_{i} \\
& +\varepsilon_{i t}
\end{aligned}
$$

where $i$ is an index of household and $t$ indicates the year of HCES round, $\gamma_{i}$ and $\mu_{\mathrm{i}}$ are time-invariant unobserved fixed effects, and $\varepsilon_{i t}$ and ${ }_{\text {it }}$ are unobserved error terms. In eq. (1), $\mathrm{X}_{\mathrm{it}}$ represents a vector of other exogenous variables affecting per capita calorie intake $\left(P C C I T A K E_{i t}\right)$ listed in Table $1 ; \alpha_{0}$ (scalar), $\alpha_{1}$ (scalar), and $\theta$ (vector) are parameters to be estimated. We have calculated variance inflation factor (vif) to check for the presence of multicollinearity. The mean VIF value was about two for all the models and ruled out any presence of multicollinearity.

We performed the regression analysis separately for each round of HCES and the pooled data combining the 2004-05 and 2011-12 rounds. A negative and statistically significant coefficient in 2004-05 round will support the hypothesis that inadequate account of FAFH led to underreporting of calorie intake for households with consumption of FAFH. A positive and statistically significant coefficient on $D F A F H_{i t}$ in $2011-$ 12 round will support the hypothesis that refinement in data collection addressed the issue of measurement error in the accounting of FAFH and contributed to the reversal of calorie intake decline. Although the results from the HCES-roundwise regressions and those from pooled model will be more or less similar, use of pooled model increases statistical efficiency of the model estimates. For the pooled sample, we include the YEAR variable and an interaction term between $D F A F H_{i t}$ and $Y E A R$ to test our hypothesis that improvements in data reporting and accounting of FAFH has a positive effect on the observed per capita calorie intake in the 2011-12 round. A positive and statistically significant coefficient on the interaction term $\left(Y E A R^{*} D F A F H_{i t}\right)$ will support our 


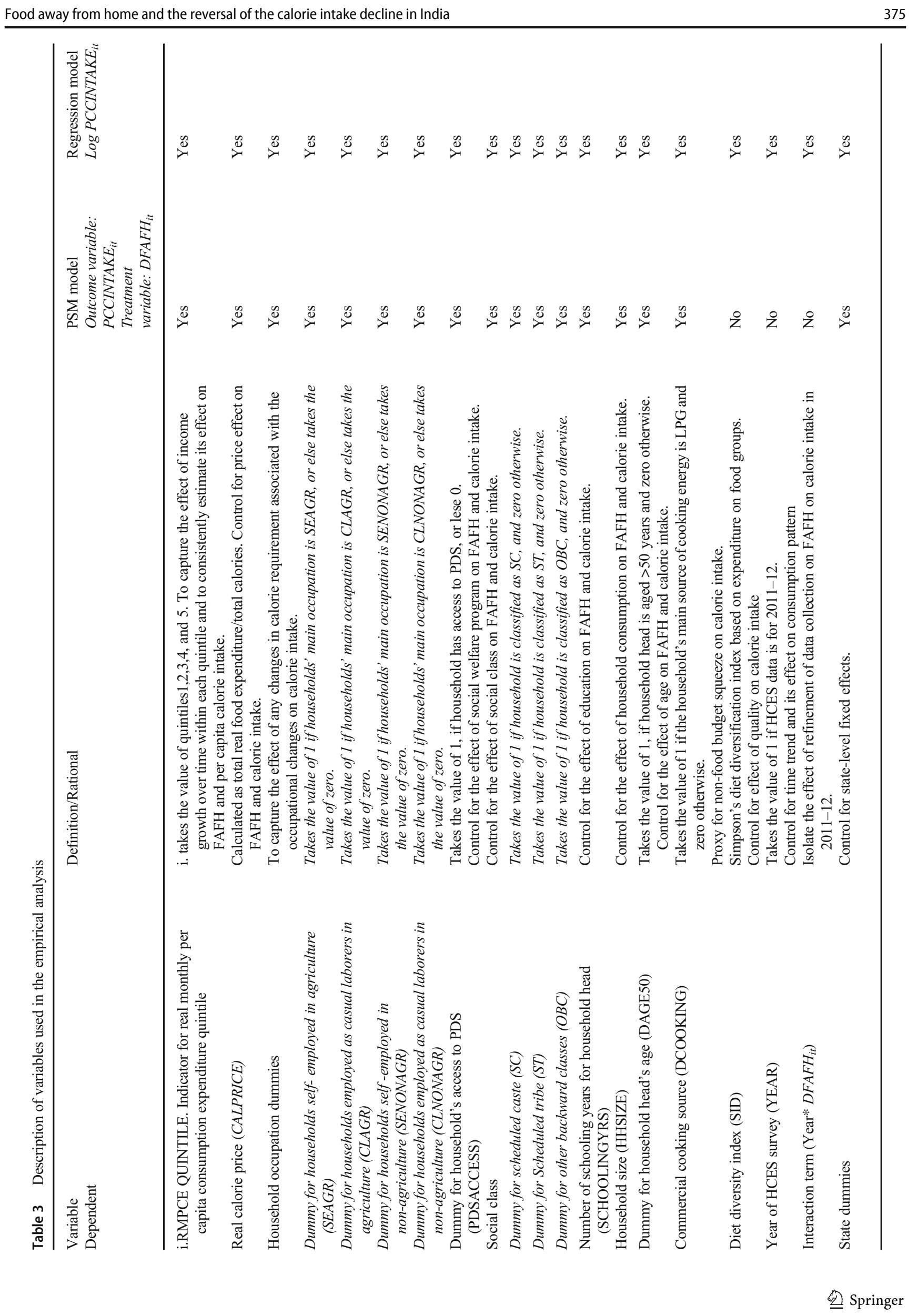


Fig. 2 a District-wise map of average per capita daily calorie intake in rural India, 2004-05. b District-wise map of average per capita daily calorie intake in rural India, 2011-12
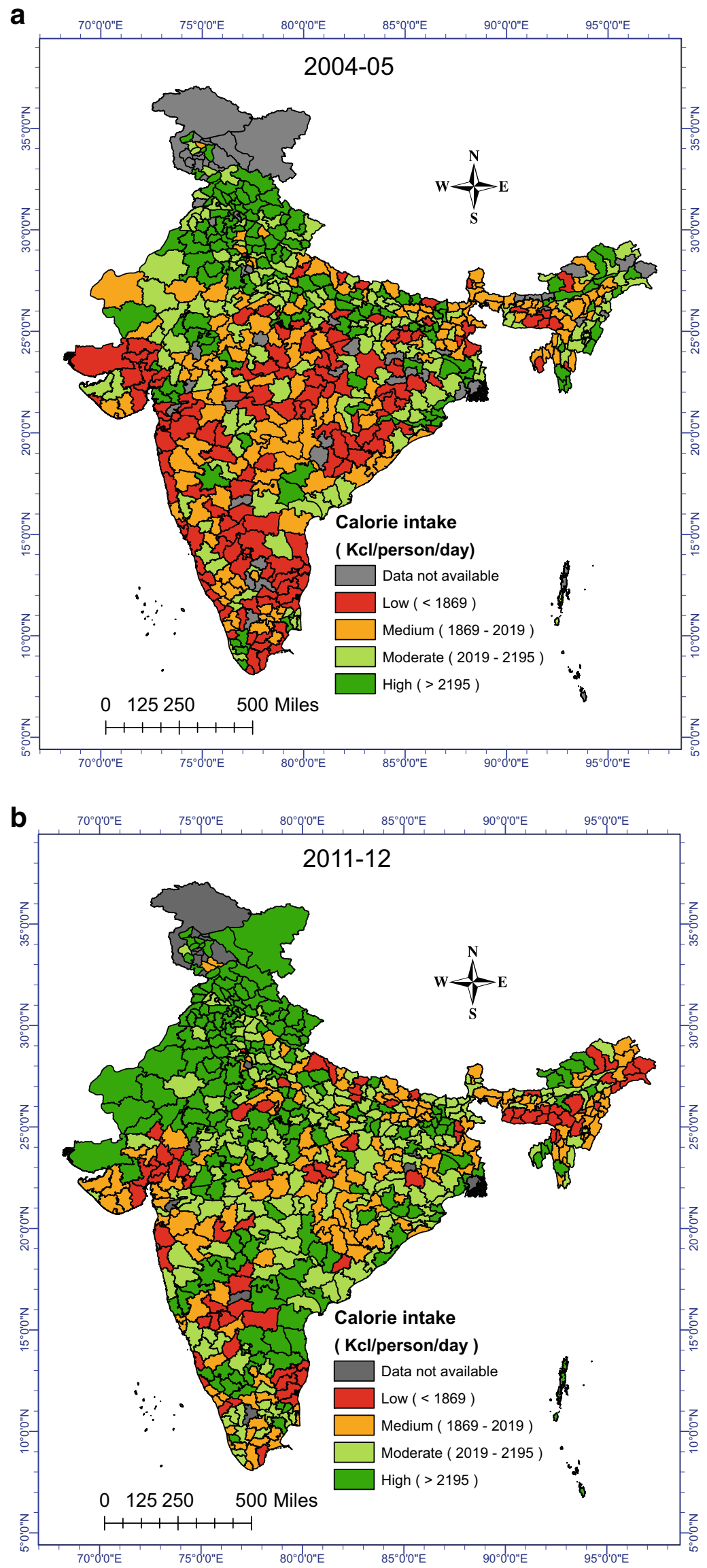
hypothesis that data improvement on FAFH is an important contributor to the reversal of the declining trend in per capita calorie intake in India. To further check the robustness of the results, the study also estimated regression models that replaced the dummy variable for FAFH $\left(D F A F H_{i t}\right)$ with the number of FAFH meals/day/person $\left(\mathrm{N} F A F H_{i t}\right)$ consumed.

\section{Results}

To understand the spatial pattern of changes in the calorie intake between the 2004-05 and 2011-12 rounds of HCES, we used household-level data to generate aggregate data on per capita calorie intake at the district level (Fig. 2a and b). It is evident from Fig. 2 that there is an overall increase in per capita calorie intake across rural India during the study period.

Table 4 compares the mean values of per capita calorie intake between the households with and without the consumption of FAFH. We find that per capita calorie intake was lower (by $109 \mathrm{Kcal} /$ person/day) for households with FAFH in 2004-05 and it was higher by $63 \mathrm{Kcal} /$ person/day in 201112. The estimate of per capita number of cooked meals in 2011-12 was 2.4 compared to the 0.27 in 2004-05.

Table 5 presents the comparison of summary statistics of key variables included in the PSM analysis and regression analyses between 2004 and 05 and 2011-12. Results from ttests comparing the mean values between rounds show that all the variables except, sex, per capita consumption expenditure quintile, and the social class dummy variable for scheduled cast (SC) are statistically significantly different at $1 \%$ levels.

Results from the treatment effects model presented in Table 6 support our hypothesis that due to the inadequate data collection and accounting of calories from FAFH, households with FAFH would have lower per capita calorie intake than those households without FAFH in 2004-05 and, because of the refinement in data collection and accounting of FAFH in 2011-12, the effect would be reversed in the 2011-12 round. Similarly, the ATET values were negative in 2004-05 and positive and statistically significant in 2011-12.
Results from the regression models are presented in Table 7. Interpretation of dummy variables in a semilogarithmic regression differs from that of continuous variable where the coefficient multiplied by 100 is equal to the percentage effect of the variable on the dependent variable. The relative effect $(\mathrm{g})$ of a dummy variable on dependent variable in a semilogarithmic regression can be expressed as $g=\exp$.(c)1 , where $\mathrm{c}$ is the dummy variable coefficient and the percentage effect is equal to $100(\mathrm{~g})=100((\exp (\mathrm{c})-1)($ Halvorsen and Palmquist 1980). Following Halvorsen and Palmquist (1980), the negative and statistically significant coefficient on DFAFHit in Model $1(-0.015)$ suggests that a $1 \%$ increase in the likelihood of eating outside home reduces the per capita calorie intake by $1.5 \%$ in $2004-05$. The positive and statistically significant coefficient on $D F A F H_{i t}$ in Model $2(0.054)$ suggests that a $1 \%$ increase in the likelihood of eating outside the home increased the per capita calorie intake by $5.5 \%$ in 2011-12. The contrasting signs of the coefficient on $D F A F H_{i t}$ in Models 1 and 2 along with the positive and statistically significant coefficient on the interaction term between $Y E A R$ and DFAFHit $\left(Y E A R^{*} D F A F H_{i t}\right)$ in Model 3 support our hypothesis that refinements in data collection and accounting of FAFH (particularly on cooked meals) in 2011-12 has a positive effect on the increased per capita calorie intake observed in 2011-12. Although not directly comparable due to the use of different rounds of HCS data, our results support the findings from Fiedler and Yadav (2017) which showed that unpacking of 'number of cooked meals' in 2007-08 round into more sub-categories in 2011-12 round addressed most of the measurement error associated with accounting of FAFH.

The results for the effect of other variables in Table 7 are mostly similar to what has been already reported in the literature on the calorie consumption puzzle. The coefficients of indicator variables for monthly real per capita expenditure quintiles (i.RMPCEQUINTILE) show that per capita calorie intake is positively associated with consumption expenditure. The negative and statistically significant coefficient on the calorie price variable suggests the inverse price-calorie intake relationship. The study finds a negative effect of diet
Table 4 Comparison of per capita calories intake with and without FAFH in rural India

\begin{tabular}{llll}
\hline Calorie Category & FAFH (No) & FAFH (Yes) & All households \\
\hline 2004-05 Round & & & \\
Grand total calories (Kcal/person/day) & 2041.8 & 1933.0 & 2000.6 \\
Number of observations & 51,204 & 26,594 & 77,797 \\
Percentage & 65.8 & 34.2 & 100 \\
2011-12 Round & & & \\
Grand total calories (Kcal/person/day) & 2050.8 & 2113.3 & 2081.9 \\
Number of observations & 32,401 & 26,455 & 58,856 \\
Percentage & 55.1 & 44.9 & 100 \\
\hline
\end{tabular}

Source: Authors 
Table 5 Summary statistics of key demographic and socioeconomic variables from the HCES

\begin{tabular}{|c|c|c|}
\hline Variable & $\begin{array}{l}\text { 2004-05 } \\
\text { Round }\end{array}$ & $\begin{array}{l}\text { 2011-12 } \\
\text { Round }\end{array}$ \\
\hline Sex (1-female, 0 -male) & $\begin{array}{l}0.106 \\
(0.308)\end{array}$ & $\begin{array}{l}0.107 \\
(0.309)\end{array}$ \\
\hline Age (years) & $\begin{array}{l}46.114 \\
(13.437)\end{array}$ & $\begin{array}{l}46.984 * * * \\
(13.229)\end{array}$ \\
\hline Land possessed (acres) & $\begin{array}{l}1.348 \\
(48.219)\end{array}$ & $\begin{array}{l}0.873 * * * \\
(1.948)\end{array}$ \\
\hline Years of schooling (years) & $\begin{array}{l}4.954 \\
(4.834)\end{array}$ & $\begin{array}{l}6.117 * * * \\
(5.340)\end{array}$ \\
\hline Household size (number) & $\begin{array}{l}5.111 \\
(2.561)\end{array}$ & $\begin{array}{l}4.809 * * * \\
(2.247)\end{array}$ \\
\hline $\begin{array}{l}\text { Indicator for monthly per capita consumption } \\
\text { expenditure quintile (i.RMPCE QUINTILE-2) }\end{array}$ & $\begin{array}{l}0.146 \\
(0.353)\end{array}$ & $\begin{array}{l}0.142 \\
(0.349)\end{array}$ \\
\hline i.RMPCE QUINTILE-3 & $\begin{array}{l}0.178 \\
(0.382)\end{array}$ & $\begin{array}{l}0.176 \\
(0.381)\end{array}$ \\
\hline i.RMPCE QUINTILE-4 & $\begin{array}{l}0.229 \\
(0.419)\end{array}$ & $\begin{array}{l}0.228 \\
(0.419)\end{array}$ \\
\hline i.RMPCE QUINTILE-5 & $\begin{array}{l}0.326 \\
(0.469)\end{array}$ & $\begin{array}{l}0.335 \\
(0.472)\end{array}$ \\
\hline Households self- employed in agriculture (1-yes, 0 -No) & $\begin{array}{l}0.351 \\
(0.477)\end{array}$ & $\begin{array}{l}0.279 * * * \\
(0.449)\end{array}$ \\
\hline Households employed as casual laborers in agriculture (1-yes, 0 -No) & $\begin{array}{l}0.147 \\
(0.354)\end{array}$ & $\begin{array}{l}0.083 * * * \\
(0.275)\end{array}$ \\
\hline Households self -employed in non-agriculture (1-yes, 0 -No) & $\begin{array}{l}0.225 \\
(0.418)\end{array}$ & $\begin{array}{l}0.257 * * * \\
(0.437)\end{array}$ \\
\hline Households employed as casual laborers in non-agriculture (1-yes, 0 -No) & $\begin{array}{l}0.109 \\
(0.313)\end{array}$ & $\begin{array}{l}0.148 * * * \\
(0.355)\end{array}$ \\
\hline Scheduled Caste-SC (1-yes, 0-No) & $\begin{array}{l}0.174 \\
(0.379)\end{array}$ & $\begin{array}{l}0.171 \\
(0.376)\end{array}$ \\
\hline Scheduled Tribe-ST (1-yes, 0-No) & $\begin{array}{l}0.161 \\
(0.368)\end{array}$ & $\begin{array}{l}0.168 * * * \\
(0.374)\end{array}$ \\
\hline Other Backward Classes-OBC (1-yes, 0-No) & $\begin{array}{l}0.379 \\
(0.485)\end{array}$ & $\begin{array}{l}0.398 * * * \\
(0.489)\end{array}$ \\
\hline Access to PDS (1-yes, 0 -No) & $\begin{array}{l}0.254 \\
(0.436)\end{array}$ & $\begin{array}{l}0.508 * * * \\
(0.499)\end{array}$ \\
\hline Real calorie price (CALPRICE) & $\begin{array}{l}1.686 \\
(1.132)\end{array}$ & $\begin{array}{l}1.839 * * * \\
(1.236)\end{array}$ \\
\hline Dummy for LPG cooking source (DLPG) & $\begin{array}{l}0.132 \\
(0.338)\end{array}$ & $\begin{array}{l}0.242 * * * \\
(0.428)\end{array}$ \\
\hline Diet diversity index (SID) & $\begin{array}{l}0.750 \\
(0.095)\end{array}$ & $\begin{array}{l}0.776^{* * * *} \\
(0.081)\end{array}$ \\
\hline Proportion of real expenditure on education (PROPEDNEXP) & $\begin{array}{l}7.125 \\
(15.862)\end{array}$ & $\begin{array}{l}15.285 \\
(31.995)\end{array}$ \\
\hline Proportion of medical related expenses (PROPMEDCEXP) & $\begin{array}{l}0.044 \\
(0.082)\end{array}$ & $\begin{array}{l}0.050 \\
(0.083)\end{array}$ \\
\hline
\end{tabular}

Note: Values in parentheses are standard deviations. $* * *$ indicates that results from t-tests comparing the mean values between rounds are statistically significantly different at $1 \%$ level 
diversification (which was calculated as Simpson's diversity index on expenditure across food groups) on calorie intake. Coefficients on dummies related to social classes (SC, ST, and OBC) show a negative and statistically significant relationship between calorie intake and disadvantaged social. The study included a dummy for commercial cooking source as a proxy for the increasing non-food expenditure incurred by most of the rural households in India. Coefficient on commercial cooking source has positive and statistically significant effect on calorie intake in 2004-05, negative and statistically significant coefficient in 2011-12, and not significant in the pooled model.

Among the household occupation dummy variables, selfemployed in agriculture (SEAGR), casual laborers in agriculture $(C L A G R)$, and self-employed in non-agriculture have positive and statistically significant effects on calorie intake, while casual labor in non-agriculture (CLNONAGR) has no statistically significant effect. As per our results, per capita calorie intake is higher for households with access to PDS (PDSACCESS) than without access to PDS. Among the demography related variables, households with household heads over 50 years of age and a higher number of years of schooling have a positive and statistically significant effect on per capita calorie intake. Findings from the study show a negative and statistically significant effect of household size on per capita calorie intake. Results from the regression model that replaced the dummy variable for consumption of FAFH with the number of FAFH meals/day/person are presented in Table 8 in Appendix. Results in Table 8 are similar to results in Table 7.

\section{Discussion}

Smith (2015) attributed measurement error in calorie intake from FAFH as a contributing factor in the 'consumption puzzle' in India. Fiedler and Yadav (2017) showed that refinements in data collection of FAFH improved the calorie estimates from FAFH. In this study, we extended the analyses of Smith (2015) and Fiedler and Yadav (2017) to analyze the effect of refinement in data collection on FAFH on the first time reversal of the declining trend in per capita calorie intake in India. Table 1 shows that Block 4 of the HCES type 1 schedule collects similar data in 2004-05 and 2011-12 rounds of HCES and there is an increasing trend towards consumption of FAFH in rural India. However, as reported in Smith (2015) and Fiedler and Yadav (2017), calorie intake estimation is based on data from Block 5 and not from Block 4. Table 2 shows the refinement in data collection on FAFH in 2011-12 round relative to the 2004-05 round.

Results from 2004-05 HCES round in Table 4 show that similar to Smith (2015), per capita calorie intake was lower for households that reported consumption of FAFH than those who did not report consumption of FAFH. However, the opposite was the case in the 2011-12 HCES round, that is per capita calorie intake was higher for households that reported consumption of FAFH than those who did not report consumption of FAFH. Tables 1, 2, 3 and 4 provide the backgorund for the empirical analyses in this study.

Summary statistics of key variables and the t-test results presented in Table 5 show an overall positive trend in the socio-demographic and economic factors that are potentially influential in consumers' decision on consumption of FAFH and per capita calorie intake and support our decision to control for these confounding factors in the empirical analyses. Comparison of results from the treatment effect model using PSM between 2004-05 and 2011-12 in Table 6 support findings from Smith (2015) that improper accounting of calorie from meals consumed outside the home is one of the potential reasons for calorie consumption puzzle in India.

Results from the regression analysis (Table 7) that controlled for confounding factors show that households with consumption of FAFH has a negative and statistically significant effect on the per capita calorie intake in 2004-05 while the effect was positive and statistically significant in 2011-12. Overall, results in Tables 6 and 7 support our hypothesis that refinements in data collection in FAFH has a positive and statistically significant effect on the reversal of the calorie intake decline in India. The effect of other variables on calorie
Table 6 Results from the treatment effect estimation model

\begin{tabular}{|c|c|c|c|c|}
\hline \multirow[t]{2}{*}{ Category } & \multicolumn{2}{|c|}{ 2004-05 Round } & \multicolumn{2}{|l|}{ 2011-12 Round } \\
\hline & Coefficient & $\mathrm{Z}$ value & Coefficient (Robust standard error) & $\mathrm{Z}$ value \\
\hline \multicolumn{5}{|c|}{ Outcome variable: Per capita calorie intake } \\
\hline ATE of FAFH & $\begin{array}{l}-2.4 \\
(4.9)\end{array}$ & -0.49 & $\begin{array}{l}116.34 * * * \\
(4.8)\end{array}$ & 24.0 \\
\hline ATET of FAFH & $\begin{array}{l}-18.5^{* * *} \\
(6.4)\end{array}$ & $-2.9 * * *$ & $\begin{array}{l}131.9 * * * \\
(5.5)\end{array}$ & 23.9 \\
\hline $\mathrm{N}$ & & & 58,782 & \\
\hline
\end{tabular}

ATE-average treatment effect; ATET-average treatment effect on the treated. *** represents the statistical significance of the coefficients at $1 \%$ level. The variables included in the treatment effect estimation model are included in Table 1 
Table 7 Results from the regression models

Variable

Dependent

Consumption of FAFH (DFAFH $H_{i t}$

Indicator for monthly per capita consumption expenditure quintile (i.RMPCE QUINTILE-2)

i.RMPCE QUINTILE-3

i.RMPCE QUINTILE-4

\section{i.RMPCE QUINTILE-5}

Real calorie price (CALPRICE)

Proportion of real expenditure on education (PROPEDNEXP)

Proportion of medical related expenses (PROPMEDCEXP)

Dummy for LPG cooking source (DLPG)

Diet diversity index (SID)

Dummy for households self- employed in agriculture (SEAGR)

Dummy for households employed as casual laborers in agriculture (CLAGR)

Dummy for households self -employed in non-agriculture (SENONAGR)

Dummy for households employed as casual laborers in non-agriculture (CLNONAGR)

Dummy for access to PDS (PDSACCESS)

Dummy for household head's age (DAGE50)

Number of schooling years for household head (SCHOOLINGYRS)

Household size (HHSIZE)

Dummy for scheduled caste (SC)

Dummy for Scheduled tribe (ST)

Dummy for other backward classes (OBC)

Year of HCES survey (YEAR)

Interaction term (Year* $\left.D F A F H_{i t}\right)$

State dummies

Constant

Number of Observations

$\mathrm{R}$-squared

Model 1

2004-05 Round

Model 2

log per capita calorie intake (Kcal/person/day)

\begin{tabular}{|c|c|c|}
\hline $\begin{array}{l}-0.015^{* * *} \\
(0.002)\end{array}$ & $\begin{array}{l}0.054 * * * \\
(0.002)\end{array}$ & $\begin{array}{l}-0.016^{* * * *} \\
(0.002)\end{array}$ \\
\hline $0.200^{* * *}$ & $0.143 * * *$ & $0.178^{* * *}$ \\
\hline (0.004) & $(0.003)$ & $(0.003)$ \\
\hline $0.311^{* * *}$ & $0.229 * * *$ & $0.279 * * *$ \\
\hline$(0.004)$ & $(0.003)$ & $(0.003)$ \\
\hline $0.421 * * *$ & $0.318 * * *$ & $0.381 * * *$ \\
\hline$(0.004)$ & $(0.004)$ & $(0.003)$ \\
\hline $0.621 * * *$ & $0.465 * * *$ & $0.560 * * *$ \\
\hline$(0.006)$ & $(0.005)$ & $(0.004)$ \\
\hline$-0.048 * * *$ & $-0.021 * * *$ & $-0.035^{* * * *}$ \\
\hline$(0.005)$ & $(0.003)$ & $(0.003)$ \\
\hline$-0.001 * * *$ & $-0.001 * * *$ & $-0.001 * * *$ \\
\hline$(0.000)$ & $(0.000)$ & $(0.000)$ \\
\hline$-0.432 * * *$ & $-0.363 * * *$ & $-0.400 * * *$ \\
\hline$(0.016)$ & $(0.014)$ & $(0.011)$ \\
\hline$-0.011 * * *$ & $-0.020 * * *$ & $-0.021 * * *$ \\
\hline$(0.003)$ & $(0.002)$ & $(0.002)$ \\
\hline$-0.319 * * *$ & $-0.445 * * *$ & $-0.375 * * *$ \\
\hline$(0.037)$ & $(0.018)$ & $(0.023)$ \\
\hline $0.052 * * *$ & $0.037 * * *$ & $0.046^{* * *}$ \\
\hline$(0.003)$ & $(0.002)$ & $(0.002)$ \\
\hline $0.026 * * *$ & $0.016^{* * * *}$ & $0.016^{* * *}$ \\
\hline$(0.004)$ & $(0.003)$ & $(0.003)$ \\
\hline $0.014 * * *$ & -0.002 & $0.007 * * *$ \\
\hline$(0.003)$ & $(0.002)$ & $(0.002)$ \\
\hline-0.004 & -0.000 & 0.001 \\
\hline (0.004) & $(0.003)$ & $(0.003)$ \\
\hline $0.030 * * *$ & $0.048 * * *$ & $0.042 * * *$ \\
\hline$(0.002)$ & $(0.002)$ & $(0.002)$ \\
\hline $0.031 * * *$ & $0.020 * * *$ & $0.026 * * *$ \\
\hline$(0.002)$ & $(0.002)$ & $(0.001)$ \\
\hline $0.001 * * *$ & 0.000 & $0.001 * * *$ \\
\hline$(0.000)$ & $(0.000)$ & $(0.000)$ \\
\hline$-0.010 * * *$ & $-0.021 * * *$ & $-0.014 * * *$ \\
\hline$(0.000)$ & $(0.000)$ & $(0.000)$ \\
\hline$-0.008 * * *$ & $-0.011 * * *$ & $-0.011 * * *$ \\
\hline$(0.002)$ & $(0.003)$ & $(0.002)$ \\
\hline$-0.016^{* * * *}$ & $-0.013 * * *$ & $-0.015 * * *$ \\
\hline$(0.003)$ & $(0.003)$ & $(0.002)$ \\
\hline$-0.004 *$ & $-0.004 *$ & $-0.005 * * *$ \\
\hline \multirow[t]{5}{*}{$(0.002)$} & $(0.002)$ & $(0.002)$ \\
\hline & & $0.026 * * *$ \\
\hline & & $(0.002)$ \\
\hline & & 0.068 *** \\
\hline & & $(0.002)$ \\
\hline Yes & Yes & Yes \\
\hline $7.632 * * *$ & $7.880 * * *$ & $7.721 * * *$ \\
\hline$(0.027)$ & $(0.016)$ & $(0.018)$ \\
\hline 77,677 & 58,782 & 136,459 \\
\hline 0.436 & 0.413 & 0.417 \\
\hline
\end{tabular}

Figures in parentheses are standard errors. ****and ** indicate the statistical significance of the coefficients at $1 \%$ and $5 \%$, respectively

intake are mostly similar to what has been already reported in the literature on the calorie consumption puzzle: overall consumption expenditure and age of the household head have a positive effect (Srivastava and Chand 2017), while calorie price (Mahajan et al. 2015), diet diversification (Basole and Basu 2015; Srivastava et al. 2016), socially disadvantaged classes (Mahadevan and Suardi 2013), and household size have negative effects (Deaton and Paxson 1998). Among these, effect of diet diversification index on calorie intake deserve special attention in the context of prevalent undernourishment, malnourishment, and chronic micronutrient deficiency in India. There are studies that show that food baskets 
of Indian households are shifting from cereals to high value food commodities such as milk, meat, fruits, vegetables, and processed foods (Meenakshi 1996; Rao 2000; Radhakrishna 2005; Srivastava et al. 2013). The implications of declining cereals consumption and increasing diversification of food basket on nutritional security depend on net nutritional intake. Srivastava et al. (2016) found a negative association between the dietary diversification index and growth in calorie intake, meaning that diet diversification has resulted in lesser calorie intake. On the other hand, Parappurathu, et al. (2019) have found evidence of a positive association between diet diversity and calorie sufficiency in eastern India. Given that diet-diversification is expected to have positive effects on intake of micro-nutrients, vitamins and minerals, it is an aspect that needs to be investigated in future research.

\section{Conclusion and implications}

Calorie intake is considered as a direct measurement of satisfaction of basic food needs and is often used to measure poverty and welfare. Due to the positive relationship between food consumption and welfare, as income increases, the under-nourishment level is expected to decrease. India experienced a consumption puzzle since the 1970s, where households' calorie intake declined over time, despite significant economic growth. This declining trend in calorie intake (consumption puzzle) was reversed for the first time in 2011-12. The present study brings new insights to the calorie consumption puzzle debate in India and investigates the effect of refinement in data collection of food consumed away from home on the first-time reversal in the declining trend of calorie intake in India. Findings from our study show that refinement in data collection on FAFH has a positive effect on the firsttime reversal of the declining trend in calorie intake in India. Incorrect estimates of calorie intake will have negative implications on the effectiveness of social welfare programs developed based on the calorie intake estimates. Results from this study that showed correcting for measurement error will improve calorie intake estimate have implications not only for India but also for other countries that use household-level consumption data to understand diets and to design social welfare programs.

Nutrient content of a given food item also depends on the form and manner in which it has been cooked and served. The data collected through HCES do not have information on qualitative aspects of foods consumed and hence our analyses do not account for this. While we recognize the challenges of using nationally representative surveys to collet qualitative and quantitative information on food consumption at household level in a country such as India, availability of such data will further improve the efficiency of calorie and nutrient intake estimations using HCES. Limitations that we faced in our study offer opportunities for improving HCES data collection and for future research.

\section{Compliance with ethical standards}

Conflict of interest The authors declared that they have no conflict of interest.

\section{Appendix}

Table 8 Results from the regression model using number of FAFH meals as a control variable

\begin{tabular}{|c|c|c|c|}
\hline \multirow{2}{*}{$\begin{array}{l}\text { Variable } \\
\text { Dependent }\end{array}$} & $\begin{array}{l}\text { Model } 12004-05 \\
\text { Round }\end{array}$ & $\begin{array}{l}\text { Model } 2 \text { 2011-12 } \\
\text { round }\end{array}$ & $\begin{array}{l}\text { Model } 3 \text { Pooled } \\
\text { sample }\end{array}$ \\
\hline & \multicolumn{3}{|c|}{$\log$ per capita calorie intake (Kcal/person/day) } \\
\hline Number of FAFH meals/day/person $\left(N F A F H_{i t}\right)$ & $\begin{array}{l}-0.114 * * * \\
(0.016)\end{array}$ & $\begin{array}{l}0.063 * * * \\
(0.002)\end{array}$ & $\begin{array}{l}-0.31 * * * \\
(0.016)\end{array}$ \\
\hline $\begin{array}{l}\text { Indicator for monthly per capita consumption } \\
\text { expenditure quintile (i.RMPCE QUINTILE-2) }\end{array}$ & $\begin{array}{l}0.197 * * * \\
(0.004)\end{array}$ & $\begin{array}{l}0.144 * * * \\
(0.003)\end{array}$ & $\begin{array}{l}0.174 * * * \\
(0.003)\end{array}$ \\
\hline i.RMPCE QUINTILE-3 & $\begin{array}{l}0.305 * * * \\
(0.004)\end{array}$ & $\begin{array}{l}0.231 * * * \\
(0.003)\end{array}$ & $\begin{array}{l}0.273 * * * \\
(0.003)\end{array}$ \\
\hline i.RMPCE QUINTILE-4 & $\begin{array}{l}0.414 * * * \\
(0.005)\end{array}$ & $\begin{array}{l}0.321 * * * \\
(0.004)\end{array}$ & $\begin{array}{l}0.374 * * * \\
(0.003)\end{array}$ \\
\hline i.RMPCE QUINTILE-5 & $\begin{array}{l}0.611 * * * \\
(0.006)\end{array}$ & $\begin{array}{l}0.471 * * * \\
(0.005)\end{array}$ & $\begin{array}{l}0.551 * * * \\
(0.004)\end{array}$ \\
\hline Real calorie price (CALPRICE) & $\begin{array}{l}-0.037 * * * \\
(0.006)\end{array}$ & $\begin{array}{l}-0.025 * * * \\
(0.004)\end{array}$ & $\begin{array}{l}-0.031 * * * \\
(0.003)\end{array}$ \\
\hline Proportion of real expenditure on education (PROPEDNEXP) & $\begin{array}{l}-0.001 * * * \\
(0.000)\end{array}$ & $\begin{array}{l}-0.001 * * * \\
(0.000)\end{array}$ & $\begin{array}{l}-0.001 * * * \\
(0.000)\end{array}$ \\
\hline
\end{tabular}


Table 8 (continued)

Variable

Dependent

$\begin{array}{lll}\begin{array}{l}\text { Model 1 2004-05 } \\ \text { Round }\end{array} & \begin{array}{l}\text { Model 2 2011-12 } \\ \text { round }\end{array} & \begin{array}{l}\text { Model 3 Pooled } \\ \text { sample }\end{array} \\ \text { log per capita calorie intake (Kcal/person/day) } & \end{array}$

Proportion of medical related expenses (PROPMEDCEXP)

$-0.419 * * *$

(0.016)

$-0.369 * * *$

$-0.394 * * *$

$-0.015 * * *$

(0.003)

(0.015)

(0.011)

Dummy for LPG cooking source (DLPG)

$-0.331 * * *$

$-0.020 * * *$

$-0.021 * * *$

(0.002)

Diet diversity index (SID)

(0.036)

$-0.417 * * *$

$-0.331 * * *$

(0.022)

Dummy for households self- employed in agriculture (SEAGR)

$0.049 * * *$

(0.003)

(0.017)

$0.045 * * *$

(0.002)

Dummy for households employed as casual laborers in agriculture (CLAGR)

$0.024 * * *$

(0.004)

$(0.002)$

$0.016 * * *$

$0.016 * * *$

(0.003)

Dummy for households self -employed in non-agriculture (SENONAGR)

$0.012 * * *$

0.003

$0.006 * * *$

(0.003)

(0.002)

Dummy for households employed as casual laborers in non-agriculture (CLNONAGR)

$-0.004$

(0.004)

$0.031 * * *$

(0.002)

$0.030 * * *$

(0.002)

$0.001 * * *$

(0.000)

Household size (HHSIZE)

Dummy for scheduled caste (SC)

$-0.010 * * *$

(0.000)

$-0.007 * * *$

(0.002)

$-0.015 * * *$

(0.003)

(0.002)

0.001

(0.002)

(0.003)

$0.042 * * *$

(0.002)

$0.025 * * *$

(0.001)

$0.001 * * *$

(0.000)

$-0.013 * * *$

(0.000)

$-0.009 * * *$

(0.002)

$-0.014 * * *$

(0.002)

$-0.003 *$

(0.002)

(0.003)

$-0.004 * * *$

(0.002)

$0.033 * * *$

(0.002)

$0.219 * * *$

(0.204)

Interaction term $\left(\right.$ Year* $\left.^{*} F A F H_{i t}\right)$

Yes

$7.639 * * *$

(0.026)

77,677

0.441
Yes

$7.867 * * *$

(0.015)

58,782

0.405
Yes

$7.691 * * *$

(0.018)

136,459

0.421

Figures in parentheses are standard errors. $* * * *$ and $* *$ indicate the statistical significance of the coefficients at $1 \%$ and $5 \%$, respectively 
Open Access This article is licensed under a Creative Commons Attribution 4.0 International License, which permits use, sharing, adaptation, distribution and reproduction in any medium or format, as long as you give appropriate credit to the original author(s) and the source, provide a link to the Creative Commons licence, and indicate if changes were made. The images or other third party material in this article are included in the article's Creative Commons licence, unless indicated otherwise in a credit line to the material. If material is not included in the article's Creative Commons licence and your intended use is not permitted by statutory regulation or exceeds the permitted use, you will need to obtain permission directly from the copyright holder. To view a copy of this licence, visit http://creativecommons.org/licenses/by/4.0/.

\section{References}

Banerjee, A., \& Duflo, E. (2011). More than 1 billion people are hungry in the world. But what if the experts are wrong? Foreign Policy, (May/June). https://foreignpolicy.com/2011/04/25/more-than-1billion-people-are-hungry-in-the-world/.

Basole, A., \& Basu, D. (2015). Fueling calorie intake decline: Householdlevel evidence from rural India. World Development, 68, 82-95.

Basu, D., \& Basole, A. (2012). The calorie consumption puzzle in India: An empirical investigation. Amherst: Political Economy Research Institute, University of Massachusetts.

Chandrasekhar, C. P., \& Ghosh, J. (2003). The calorie consumption puzzle. The Hindu Business Line. Retrieved from https://www. thehindubusinessline.com/2003/02/11/stories/2003021100210900. htm

Deaton, A., \& Drèze, J. (2002). Poverty and inequality in India: A reexamination. Economic and Political Weekly, 36(36), 3729-3748.

Deaton, A., \& Drèze, J. P. (2009). Food and nutrition in India: Facts and interpretations. Economic and Political Weekly, 44(7), 42-65.

Deaton, A., \& Paxson, C. (1998). Economies of scale, household size, and the demand for food. Journal of Political Economy, 106(5), 897-930.

Duh, J., \& Spears, D. (2017). Health and hunger: Disease, energy needs, and the Indian calorie consumption puzzle. The Economic Journal, 127(606), 2378-2409. https://doi.org/10.1111/ecoj.12417.

Eli, S., \& Li, N. (2012). Can caloric needs explain three food consumption puzzles? Evidence from India. Mimeo: University of Toronto.

Fiedler, J. L., \& Yadav, S. (2017). How can we better capture food away from home? Lessons from India's linking person-level meal and household-level food data. Food Policy, 72, 81-93. https://doi.org/ 10.1016/j.foodpol.2017.08.015.

Halvorsen, R., \& Palmquist, R. (1980). The interpretation of dummy variables in semilogarithmic equations. The American Economic Review, 70(3), 474-475.

Mahadevan, R., \& Suardi, S. (2013). Is there a role for caste and religion in food security policy? A look at rural India. Economic Modelling, $31,58-69$.

Mahajan, S., Sousa-Poza, A., \& Datta, K. K. (2015). Differential effects of rising food prices on Indian households differing in income. Food Security, 7, 1043-1053.

Meenakshi, J. V. (1996). How important are changes in taste: A state level analysis of food demand. Economic and Political Weekly, 31(50), 3265-3269.
Meenakshi, J. V. (2016). Trends in the triple burden of malnutrition in India (pp. 2454-1427). New Delhi: Delhi School of Economics ISSN No.

NFHS. (2015). National Family Health Survey (NFHS-4): 2015-16. Mumbai: Ministry of Health and Family Welfare.

NNMB. (2012). Diet and nutritional status of rural population, prevalence of hypertension, diabetes among adults and infants, and young child feeding practices. Hyderabad: National Institute of Nutrition.

NSSO. (2014a). Household consumption of various goods and services in India, 2011-12. National Sample Survey Office.

NSSO. (2014b). Nutritional intake in India:2011-12. National Sample Survey Office, Ministry of Statistics and Programme Implementation Report No. 560 (68/1.0/3).

Parapuurathu, S., Kumar, A., Bantilan, M. C. S., \& Joshi, P. K. (2015). Food consumption patterns and dietary diversity in eastern India: Evidence from village level studies (VLS). Food Security, 7, 10311042.

Patnaik, U. (2010). A critical look at some propositions on consumption and poverty. Economic and Political Weekly, 45(6), 74-80.

Radhakrishna, R. (2005). Food and nutritional security for the poor. Economic and Political Weekly, 40(18), 1817-1821.

Rao, C. H. (2000). Declining demand for food grains in rural India: Causes and implications. Economic and Political Weekly, 35(4), 201-206.

Sen, A. (2000). Estimates of consumer expenditure and its distribution: Statistical priorities after NSS. Economic and Political Weekly, 35(51), 4499-4501.

Smith, L. (2015). The great Indian calorie debate: Explaining rising undernourishment during India's rapid economic growth. Food Policy, $50,53-67$.

Srivastava, S. K., \& Chand, R. (2017). Tracking transition in calorieintake among Indian households: Insights and policy implications. Agricultural Economics Research Review, 30(1), 23-35.

Srivastava, S. K., Mathur, V. C., Sivaramane, N., Kumar, R., Hasan, R., \& Meena, P. C. (2013). Unravelling food basket of Indian households: Revisiting underlying changes and future demand. Indian Journal of Agricultural Research, 68(4), 535-551.

Srivastava, S. K., Balaji, S. J., \& Kolady, D. (2016). Is there a convergence in dietary energy intake among expenditure-classes in India. Agricultural Economics Research Review, 29, 119-128.

WHO. (2019). Global and regional food consumption patterns and trends. World Health Organization. Available at: https://www.who.int/ nutrition/topics/3_foodconsumption/en/. Accessed 3/21/2019.

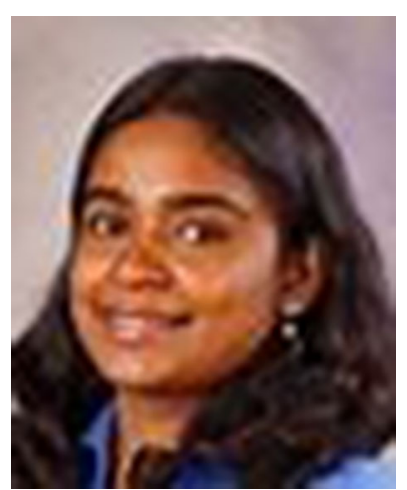

Deepthi E. Kolady is an Assistant Professor in the Ness School of Management and Economics at South Dakota State University. She received her Ph.D. in Agricultural Economics from Dyson School of Management and Economics at Cornell University. Her research focuses on producers and consumers decision making in the context of farming and food systems. 


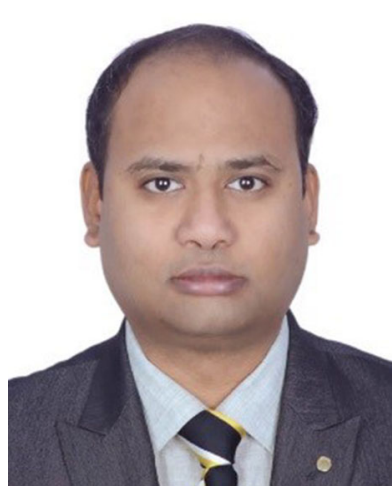

Shivendra Kumar Srivastava is a researcher at ICAR-National Institute of Agricultural Economics and Policy Research, New Delhi in India. He holds a $\mathrm{Ph} . \mathrm{D}$. in agricultural economics from the Indian Agricultural Research Institute, New Delhi. His research areas include sustainable agriculture, food \& nutritional security and policy analysis. He also holds faculty position in Division of Agricultural Economics, ICARIndian Agricultural Research Institute, New Delhi.

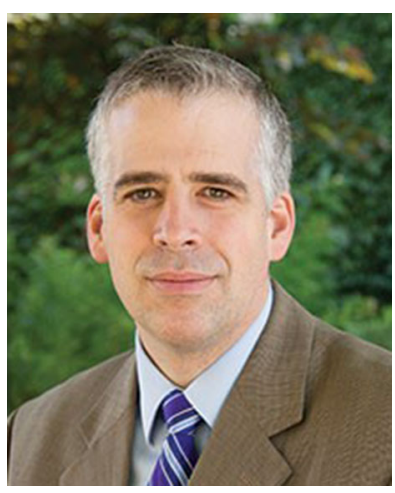

David Just is the Susan Eckert Lynch Professorship in Science and Business in the Charles $\mathrm{H}$. Dyson School of Applied Economics and Management at Cornell University. He received his $\mathrm{PhD}$ and MSc in the field of Agricultural and Resource Economics at the University of California Berkeley in 2001 and 1999 respectively. He has previously served as director of the graduate program and director of professional degree programs in the Dyson School, and currently serves as Area Coordinator for Applied Economics and Policy in the S.C. Johnson College of Business. He has also served as president of the Northeastern Agricultural and Resource Economics Association.

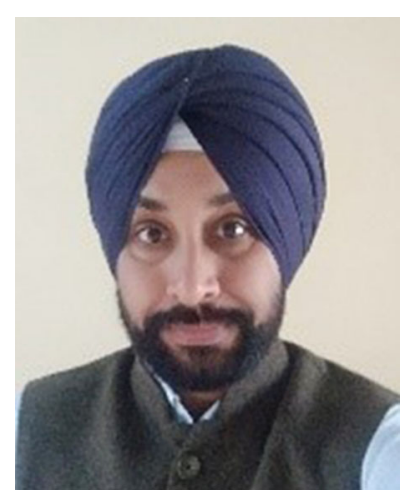

Jaspal Singh completed his Masters degree from Punjabi University, Patiala (campus) in Economics, and he has completed his M. Phil and Ph. D in Economics from Department of Regional Planning and Economic Growth, Barkatullah University, Bhopal. Dr. Singh is presently working as a consultant in National Institution for Transforming India (NITI Aayog), Govt. of India, New Delhi. Prior to joining NITI Aayog, Dr. Singh was working in ICAR-National Institute of Agricultural Economics and Policy Research, New Delhi. 